\title{
CONTRIBUTION OF MUNICIPALITIES TO THE CITIES' SUSTAINABLE PHYSIOGNOMY. RECORDING LOCAL'S OPINIONS AND PERCEPTIONS. THE CASE OF KALLITHEA
}

\author{
R. MITOULA, H. THEODOROPOULOU, D. KARNABOS \& K. APOSTOLOPOULOS \\ Department Home Economics \& Ecology, Harokopio University of Athens, Greece.
}

\begin{abstract}
The present paper investigates the input of a Local Administration Organisation (LAO) of the urban Municipality of Kallithea to its sustainable physiognomy. The investigation takes place in a period when global and, in particular, European interest for the protection and the elevation of the physiognomy of cities is particularly intense. Through the phenomenon of globalisation and international uniformity, cities today are characterised by the absence of identity and local particularity. The protection and elevation of the physiognomy of a city does not only concern the aesthetic field, but the total perception that a resident or visitor creates. This may be achieved through the combination of actions and more generally on a multi-level basis, so much in sectors such as city planning, circulation, energy, social and financial structures in the city, as with interventions on the culture and the protection of the environment. When people mention the environment, they are not speaking only of the natural environment, but also of the cultural, social and financial environment; they are essentially speaking of sustainable development of cities. Local administration today can play a large correctional and protective role. It can be a determining factor in the creation of a sustainable urban environment, in the protection and elevation of the physiognomy of cities, as it is the institution that is closest to citizens. This can be put into effect with the embodiment of local environmental policies within financial and social policies. At the same time, by training and motivating citizens towards the promotion of sustainable development, by projecting models of cooperation between state, private and social bodies, the municipality can direct the urban societies towards the protection of the physiognomy of their cities. Keywords: cities, municipalities, cities' sustainable physiognomy.
\end{abstract}

\section{INTRODUCTION}

The present project investigates the contribution of a Local Administration Organisation (LAO) of the Municipality of Kallithea towards the formation of its physiognomy. The investigation takes place in a period when global, and in particular, European interest for the protection and the elevation of the nature of cities is particularly intense. Within this framework, the investigation has concentrated on the effect of actions, interventions, but also omissions of the municipality and its legal entities on the formation of Kallithea's physiognomy, taking into account the institutional and financial potential of an LAO, but also the particular historical and social developments in the city. Specifically, a further aim of the paper is that the result of the present research could be implicated to other urban regions that have similar characteristics with the city of Kallithea. These cities can adopt similar actions and interventions to their regions.

What do we mean, however, with the term 'physiognomy of a city'? The physiognomy of a place is the result of the total perception, the true sentimental and ideological image that this place offers to its residents and visitors [1].

The nature of a place is directly affected by the time, the place combined with the activities, the characteristics, the form of the structured and natural environment, the speech, the myths, the history, as well as the emotional and psychological situations created by the interaction of the above factors. The physiognomy is not limited to the mere description of the characteristics of a place, but it also refers to its entity, the way with which the people living in a place put into effect the potential and virtues of the place and their own, thus developing to a considerable degree a feeling of awareness of the place, a particular culture, an outline of a collective awareness [2]. 
The physiognomy of a place is primarily based on and elevated by the aesthetic judgement about it, the outlines of the place, its atmosphere, and this is why priority is given in this project to the aesthetic image that a city presents. Thus, the location of a city's nature necessarily transcends the meticulous study of the functioning of the urban landscape, which aims at the production of perceptual representations. When the concepts of elevation and protection of physiognomy are mentioned, the aim is a good physiognomy, the concept of goodness. An important group of elements that interfere not only with the formation of the character but also with the elevation of the physiognomy of a city are those referring to its uses and functions [3].

Through the phenomenon of globalisation and international uniformity, cities today are characterised by the absence of identity and local particularity. The protection and elevation of the physiognomy of a city does not only concern the aesthetic field, but the total perception that a resident or visitor creates. This may be achieved through the combination of actions and more generally on a multilevel basis, so much in sectors such as city planning, circulation, energy, social and financial structures in the city, as with interventions on the culture and the protection of the environment [4]. When people mention the environment, they are not speaking only of the natural environment, but also of the cultural, social and financial environment; they are essentially speaking of sustainable development of cities [5].

Urban planning, besides being occupied with programming and planning the urban through the use of land, also deals directly with its aesthetics and nature [6]. Urban restructuring brings considerable results to the improvement of the natural and structured environment of large cities, while modern trends in land use improve the residents' quality of life, since there is an improvement in the quality of air, a reduction of air and sound pollution, energy saving, and considerable improvement of the aesthetics of residents and cities [7].

Local administration today can play a large correctional and protective role. It can be a determining factor in the creation of a sustainable urban environment, in the protection and elevation of the physiognomy of cities, as it is the institution that is closest to citizens [8]. This can be put into effect with the embodiment of local environmental policies within financial and social policies. At the same time, by training and motivating citizens towards the promotion of sustainable development, by projecting models of cooperation between state, private and social bodies, the municipality can direct the urban societies towards the protection of the physiognomy of their cities [9].

\section{KALITHEA'S PHYSIOGNOMY}

Kallithea is a city that began its history about 120 years ago as a suburb of Athens. From an area with country homes and later residence for the bourgeoisie of Athens, it became one of the greatest destinations of the refugees from the Asia Minor disaster [10]. This development, combined with the later arrival of refugees, both internal from agricultural and island regions, and external from countries of the former Soviet Union, has led to the current image of the city. Overpopulation in the city of Kallithea in the past few decades has brought on serious problems. The population that moved from rural areas towards urban centres does not identify emotionally with the area of residence [11]. A result of the coincidental accumulation of population in the city is the inability to form a uniform nature, since thousands of citizens choose to reside in Kallithea due to low rents or due to the ease of transport, and then they move away with the same ease.

Generally, Kallithea is a municipality of the Attica basin that had a street plan. With the General Urban Plan approved in 1989 and revised in 2005, the local government made an effort to demarcate land use into zones, relieve the population of disagreeable and polluting uses and stabilise it [12]. The exponential increase of population after 1960 gradually led to the weakening of the 'Kallithean' concept as an element of differentiation and reference [13]. Today, many of its residents continue to 
make up distinct cultural unities, depending on their lands of origin, as in particular Pontians, Constantinopolites or Cretans.

The city's architectural heritage is particularly important. It includes homes, as well as Public Benefit Foundation buildings of various eras, of important historical and architectural value. This valuable architectural wealth constitutes an important factor of formation and preservation of the physiognomy of the city [14]. It is noted that its further elevation following actions made by the municipality could stimulate the feeling of identification among the citizens of the city, creating strong ties of historical memory, thus improving the quality of the structured environment in the city significantly [15].

The restructuring of land use for functional and environmental reasons, the conservation of low building volumes and the introduction of urban landscape elements by axes and zones are necessary elements for future planning in the city. At the same time, changes in the legal framework are also necessary, in order to create more free areas, special aesthetic interventions, projection of the historic elements and the view, restructuring of the Public Garden area of refugee housing, existence of accessibility and promotion of transport without the use of the car, airing and better perceptual image of the city, further creation of pedestrian zones and widening of existing pavements [16]. An important new parameter for future urban planning is the turning of land use towards the sea following the donation of the Stavros Niarchos foundation for the creation of the modern and of great aesthetic value architectural projects of the National Opera House and the National Library, and also the post-Olympics utilisation of the Beach Volley venue as a modern summer 'Lycabettus'.

In addition, from early times, Kallithea constituted a centre of attraction for spiritual people. This was aided by the appearance, from the first years of its life, of important educational foundations such as the House for the Blind, the Harokopio School, the Sivitanidio School and the Pantio School [17]. Also, many scholars resided in Kallithea, especially painters, who affected the social and cultural life of the city significantly (G. Filaretos, G. Kremos, S. Laskaridou, K. Maleas, G. Griparis, G. Kordatos etc.). What, however, made the city particularly known was the special musical stage in Tzitzifies and Syggrou Avenue, which in its golden era hosted what today is called Rebetiko, thus creating an atmosphere relative to this type of music [18].

Generally, the change of social composition has been constant, a result of the constant internal and external refugee movements it accepted, but also a result of the main financial activities. In the past 80 years, the city is dominated mainly by suburban classes. This is either because the main productive activity in the city was handicrafts or industry, as between 1920 and 1980, either because the tertiary sector - that of services - prevails, as is the case today [19]. However, the particularly interesting element of the city, which strongly affects the formation of its physiognomy, is the harmonious co-existence of a multicultural whole, made up of internal refugees mainly from the surrounding rural areas, of Pontians and other refugees and of financial immigrants moving to Kallithea mainly from Albania, the countries of the former Soviet Union, and Egypt.

Finally, the activation of the Municipality of Kallithea towards reducing energy consumption and promoting renewable sources may be an important effort for the improvement of the structured and natural environment of the city [20]. It is a field of action where the potential of local administration is particularly important due to the immediate relationship of the institution with the citizens; consumer behaviours that are friendly towards the environment can thus be promoted, which will affect the city's physiognomy positively.

\section{INSTITUTIONAL POTENTIAL OF THE MUNICIPALITY OF KALLITHEA}

The Municipality of Kallithea can improve the physiognomy of the city significantly, taking action in sectors where Local Administration has the potential to intervene institutionally. Further on in the 
present text, the way that this can happen is proven. In general, the main concern of the LAO is the promotion of social and financial interests, as well as cultural, spiritual and athletic interests of the residents [21]. Within this framework, duties of the LAO include: infrastructure works, the collection of rubbish, urban planning, the protection of socially vulnerable groups, the protection of the environment, the creation and maintenance of green areas, play areas and other public spaces, activities connected to welfare and public health, education and training, culture, sport, traffic, parking, and the local economy [22]. In the latest Municipality and Community Code (2006), the responsibilities of the LAO are divided into the following seven sectors: Development-Environment-Quality of Life and good functioning of urban and housing estates, Occupation, Social Protection and Solidarity, Education, Culture, Sport and Civil Protection.

The Municipality of Kallithea, throughout its history, has followed the course of the institution of Local Administration, a course that is characterised, even to date, by conflict with the central government, demands for resources and responsibilities, so that the institution can respond to the needs of the citizens. Up until the first post-dictatorship periods, the municipality had a small technical service, which could not support large developmental programmes. The funding resources for public works were loans, state funding and self funding, while later on European Programmes were added to the list.

The regular income for the Municipality of Kallithea for the last fiscal year of 2005, for which there is information, amounts to $30 \mathrm{M}$. Euros, with cleaning taxes, real estate taxes, electrical lighting taxes and regular financial support of the municipality from Central Self-Contained Resources as the main sources, while financing for investments amount to 6.630.000 Euros. Of these amounts, only 434.000 come from European Union resources. The greatest expenditures are made by the cleaning service, especially personnel salaries. The amount left over for works is 4.370.000 Euros, only $10 \%$ of the total expenditure [23].

At the same time, in the past 20 years, the Municipality of Kallithea has created municipal undertakings, mainly concerned with culture, welfare, the execution of works and the elaboration of studies, education, promotion to employment, advertising and carrying out of European Programmes [24]. At the same time, the older Public Law Bodies and Institutions are also functioning, and occupying themselves with sport, culture, children and the third age. The municipality is soon to reform the function of its municipal undertakings, based on the new Municipality and Community Code.

According to the above and evaluating the contribution of the undertakings and other legal entities of the Municipality of Kallithea on the formation of the city's nature, the following are noted:

The functioning of the Legal Entities contributes to the increase of employment, which is achieved either directly or indirectly through the increase of resident employability, as well as the promotion of employment in vulnerable social groups such as women, people with special needs, returning refugees, former drug users, people with prolonged unemployment et al. This increase contributes positively to the physiognomy of Kallithea as it affects the human chain, which means the relationships among the citizens and their employment state, fighting the separation into zones and promoting cooperation for the benefit of the city.

There are overlapping actions of the Legal Entities in the Municipality of Kallithea, such as in culture or accompanying services, while there is a lack of a complete strategic development plan for all the legal entities; also, for many of these an update of their articles of association is necessary, in order to add modern actions that are necessary for the increase of the social capital or the improvement of the physiognomy of the city, according to developments in the institution of local administration.

The development of Legal Entity activities often clashes with the financial difficulties the Municipality of Kallithea is facing, in the same way as other Municipalities, while it also clashes with the fact that the activity of each Legal entity is made up of the ability of the person in charge. 
There is a notable insufficiency in European Programme absorption in various fields of action of the Legal Entities, due to the absence of education and know-how of the workers and members of the Boards, due to deficiencies in the articles of association, but also due to central government delays. A minimal number of infrastructure works, such as the restructuring of the surrounding areas of the Harokopio University, incline support works at Sikelia Hill and the construction of the 3rd Kindergarten, have been made with funds from the Third Community Support Framework.

Despite the multiformity of actions developed by the Legal Entities of the Municipality of Kallithea, very few residents are aware of almost all actions.

Apart from the Undertakings and the Legal Entities of the Municipality of Kallithea, the action of Non-Governmental Organisations is also important; because of the important actions they take on their flexibility and their effectiveness, these organisations constitute a new dynamic framework for the participation of citizens, but also of associates from Local Administration, in an effort to maintain and improve the physiognomy of cities [25]. The contribution of NGOs towards the formation of Kallithea's physiognomy, but also towards the increase of the social capital of the city is considerably important [26]. Nevertheless, it could be more definitive if these Organisations took actions relative to the natural and structured environment, together with local development, if they used technological applications more, if they ensured access to important funding and if they could affect decision centres more [27]. By contributing to the operation of the city's NGOs and connecting with them, the Municipality of Kallithea can ensure important cooperation in the attempt to improve the physiognomy of Kallithea.

\section{RESEARCH AND INTERVIEW}

\subsection{A. Research}

Based on the above and with the aim to elevate the most important elements that make up the nature of the city of Kallithea, in order to investigate if and to what extent there has been an effect of the municipality on the formation of its nature, and also whether the activities of the municipality are known to the citizens, a research was performed using questionnaires.

The research was performed on a sample of 360 residents of Kallithea and 300 of them reacted. The collection of the information took place via the method of personal interviews. The selection of the sample was simple stratified random sampling, based on the geographical distribution of the population, since the city was separated longitudinally into four neighbourhoods of almost equal size, which portray relatively similar characteristics. After the completion of the questionnaires followed the codification of the variables and the entry of the data into the program SPSS.

Question 1: Mention what you consider positive characteristics of the city of Kallithea (Classification from 1 to 5)

\begin{tabular}{llll}
\hline None & 1,0 & Existence of universities & 2,95 \\
Transport & 2,01 & Hospitable people & 3,06 \\
Market & 2,05 & Cultural activities & 3,08 \\
Urban planning & 2,23 & Entertainment-leisure choices & 3,09 \\
Geographical position & 2,44 & Security & 3,21 \\
Sea & 2,70 & Cheap accommodation & 3,39 \\
Services & 2,75 & Employment opportunities & 3,56 \\
Climate & 2,90 & & \\
\hline
\end{tabular}


An important finding in the above question is that the majority of the residents of Kallithea consider that the city has no positive characteristic. Of those who describe positive characteristics in the city, most mention its transport infrastructure, its developed market and the existence of satisfactory services. All of the above are connected with the existence of a good urban plan, its good geographical position, the existence of the sea, as well as the good climate of the city. The existence of two universities in Kallithea probably goes unnoticed by its residents, who have obviously not noticed the positive associations of tertiary education with the financial and cultural life of the city. Residents do not consider the entertainment choices or cultural life as positive characteristics of the city, while they do not consider that it offers security, employment opportunities or cheap accommodation.

Question 2: Mention which you consider negative characteristics of the city of Kallithea. (Classification from 1 to 5 )

\begin{tabular}{llll}
\hline Cleanliness & 1,93 & Immigrants & 3,23 \\
Lack of green areas & 2,23 & Lack of free/public spaces & 3,42 \\
Traffic & 2,62 & Lack of lighting & 3,50 \\
Criminality & 2,71 & Drugs & 3,51 \\
Lack of parking spaces & 2,89 & Lack of cultural/sports events & 3,57 \\
Noise & 2,91 & Impersonal urban - absence & 3,83 \\
Environmental pollution & 2,98 & of neighbourhood conditions & \\
Crowded city & 3,00 & Lack of services & 4,05 \\
\hline
\end{tabular}

From the findings of the above question it seems that the residents of Kallithea consider environmental issues as more important, as cleanliness, the lack of green areas, the noise and environmental pollution take up the first places. The fact that the noise problem is in such a high position is impressive, and it shows a new aspect of the problems in an urban environment, especially if we note that the noise does not stem from industrial activities, since these have almost ceased to exist in the city. Issues concerning the environment, such as the fact that the city is characterised as densely structured and has a lack of free spaces, are found in the following places, while the traffic and the lack of parking spaces, together with criminality and the strong presence of immigrants are also important problems.

An important finding is the trend showing that young people consider the pollution in the city as a negative element; this proves that they are more sensitised towards the environment. It is noted that most of the negative elements of the city can be dealt with by local politicians, proving that the municipality can contribute to the improvement of the nature of the city of Kallithea.

Question 3: Do you believe that the Municipality of Kallithea has contributed to the development of positive elements in the city?

By adding categories 1,2 and categories 4,5 and comparing the results we reach the following results: those that consider that the Municipality of Kallithea has contributed a lot or considerably to the development of positive elements in the city are a mere $14.6 \%$ of the interviewees, and they are to a great extent fewer than those $(63.5 \%)$ who consider that the municipality has not contributed at all or has contributed a little in the development of the positive elements of the city. There are $22 \%$ of citizens who consider that the Municipality of Kallithea has contributed moderately to the formation of the positive elements of the city. By analysing the above findings, we can presume that the negative opinion of Kallithea residents concerning the actions of the municipality may stem either from the current state of the city or from their acknowledgement that the institution of Local Administration cannot contribute to the development of the city and the formation of its physiognomy. 
Question 4: What works do you believe must take place? (unprompted answer)

The interviewees were given the option to provide more than one answer. From the analysis of the answers, it emerges that one out of two Kallithea residents (48.3\%) desire parking spaces to be made. Nearly the same percentage $(46.7 \%)$ desire more green areas, while a considerable number believe that works must be performed in squares (30\%) and roads $(18.3 \%)$. A considerable percentage of Kallithea residents believe that works must be performed in schools $(19.7 \%)$, pavement restructuring ((17.3\%) and the creation of pedestrian areas $(12.7 \%)$, while $15.7 \%$ ask for sanitation infrastructure, such as bins and baskets. 20.7 percent desire lighting works, $13 \%$ ask for antiflooding works, and $9.3 \%$ desire building and facade restructuring. Lastly, few people have comprehended the value of construction of bicycle tracks in the city in order to reduce traffic and pollution $(4.0 \%)$.

Question 5: Do you consider that the promotion of energy saving methods and renewable energy sources for the protection of the environment should be an important priority of the Municipality of Kallithea?

From the analysis of the above answers it emerges that Kallithea residents have understood the need for implementation of energy saving policies on a municipal level. The pollution of the environment, the large expenditures on energy, particularly made by home users, the knowledge of the global energy problem, have prompted $57.8 \%$ of the citizens to desire considerably and moderately that the municipality exerts such policies. On the other hand, $24.4 \%$ of the residents appear to be completely non-sensitised towards the matter of saving energy. Energy saving applications in construction may positively affect the formation of the physiognomy of the city, at the same time ensuring the protection of the environment [28].

Question 6: The Municipality of Kallithea possesses the following Legal Entities. Which of these are you familiar with?

The answers given to the above question reveal that Kindergartens are in the first place of recognisability (71.9\%), followed by Centres for the Open Protection of the Elderly (67.4\%), the Sport Organisation (60.1\%) and the Cultural Organisation (55.4\%). Then follow the Municipal Services Providing Undertaking (44.4\%), the Centre for Professional Vocation (43.4\%), the Public Undertaking for Cultural and Social Development (36.5\%) and the Public Technical Works Undertaking (36.4\%). From the above it is concluded that the Municipal Public Law Bodies and Institutions are more familiar than the Municipal Undertakings, as they are in the first four places. Their recognisability percentages, in fact, surpass 50\%, contrary to the Municipal Undertakings. An important finding is the fact that almost two-thirds of the interviewees are not familiar with the last two Municipal Undertakings. However, more than two-thirds of the interviewees are familiar with the two first Municipal Public Law Bodies and Institutions. Despite their ambitious foreseen targets, Municipal Undertakings are having difficulty contributing to the formation of the nature of the city. In contrast, it seems that Public Law Bodies and Institutions of the Municipality of Kallithea have a greater effect on the formation of the city's physiognomy.

Question 7: Do you know if the Municipality of Kallithea has used European Programmes for the effectuation of its works (e.g. 3rd Community Support Framework). If yes, which of these works are you aware of? (Spontaneous response)

From the analysis of the above, it emerges that Kallithea residents consider that the municipality does not use European Programmes for the effectuation of its works (71\%), despite the fact that the European contribution to the formation of a city's nature is particularly important. Among those who answered positively, the most well known work was the Young People Information Centre (42.4\%). Following this, with a considerable difference are the restructuring of the area surrounding Harokopio 
University (22.9\%), the study and construction of the 1st Municipal Kindergarten (12.6\%) and the Employment Pylons with the same percentage. The recent work of the 3rd Community Support Framework concerning incline support at Sikelia Hill is completely unknown, as well as the Centre for Accompanying Supporting Services and Centres for Creative Occupation for Children, which have been operating for several years [29].

\subsection{B. Interview}

After completing the above survey, we got the results and processed them. In our efforts to produce more reliable results, we decided to ask relative questions to the political authorities that make decisions, so as to be informed of the other side's opinion. In this case, since our study concerns the municipality, we contacted the authorities of the Municipality of Kallithea. From the interview the following results are revealed. To our question about the city's strongpoint, the answer was 'the geographical location'. That is the focal point on which it is located in Attica, between Athens and Piraeus, near the sea and near the centre. To our question about the city's weakest point, the answer was 'the dense structure', which is the result of urbanism during the $60 \mathrm{~s}, 70 \mathrm{~s}$ and $80 \mathrm{~s}$.

When asked about what the municipality does for the environment, the answer was that the city for years has advanced the issues of waste management. Firstly they placed 900 blue bins in many parts of the city and four specialised garbage trucks for transfer. At the same time, they started an information and public awareness campaign to reduce the volume of waste at its source.

Regarding the expansion of green areas, the Municipality has already made efforts in the past. Now they move onto further plantings. The Municipality participates in the programme of ECAC 'Life in the city', which has included a work related with school terrace garden of the St. Nicholas school unit. It is underlined that an urban regeneration, construction of bioclimatic buildings, etc. are introduced to the program in regard. Generally, the strengthening of the program, promotes the use and exploitation of renewable energy sources from the municipality.

When asked what the Municipality does in order to maintain the physiognomy of the city, the answer was that the city tries to preserve the historical memory of the people via symbols that have to do with the city. Names of historical figures of importance have been given to cultural and sports centres, roads and squares, such as Davaki, Philaretoy etc. Also, the Municipality supports funding of cultural events, regenerates important emblematic buildings of the city, such as the red building, the Peano and others. In matters regarding green areas, it always tries to use plants, which are in accordance to the physiognomy of the Greek landscape (citrus).

To our question on the projects that the municipality has scheduled in the city, the answer was: renovation of traditional buildings, rebuilding of sidewalks and parking station near the Avenue Siggrou, where the parking problem is more intense because of dense structure.

When asked if the Municipality works with NGOs and other organizations on issues that promote the conservation of the physiognomy of the city, the response was positive. The Municipality cooperates and finances operations of such entities to organize events and often houses such events in its buildings. To the question if the Municipality takes advantage of the EU funding for infrastructure projects and projects that promote the good physiognomy of the city, the answer was positive. The municipality has used European programmes for the development of the Sicilian hill, for the formation of the park across the Harokopio University. With the European funding it also built the municipality nursery, and as said above, European funding will go to construction of bioclimatic buildings, restorations, pedestrian zones, etc. 


\section{CONCLUSIONS}

The more general conclusions that arise from the whole of the theoretical and experiential study are as follows:

The physiognomy of an area is based on and elevated first of all by the aesthetic judgement for each land; it is directly affected by time and place, in combination with the activities, the characteristics, the form of the structured and natural environment, the myths, the history, the emotional and psychological states that it bears. For this reason, the study of the aesthetic image that a city presents is particularly important.

Also, in our days, due to the significant intervention of local administration, the institutional framework can become a preferential field for the application of policies and the improvement of the perceptual image of the city. Municipal authorities in Kallithea have the potential to make many measures in the direction of improving the structured environment.

Kallithea has characteristics that emerge from the uniformity of today's globalised cities, but also from its particular history. Residents are not satisfied by the action of the Municipality of Kallithea in all sectors they were asked about. Despite this, it was found that the Municipality of Kallithea does have a relative contribution to the formation of the city's physiognomy. Its actions have had direct and indirect effects on the formation of the city's current natural and structured environment. However, its contribution has not been adequate to improve or at least maintain its nature. This is due to innate weaknesses within the institution of local administration, but it is also due to actions or failures of the municipality's administrations. Especially in the past few years, when the potential for EU funding has been increased, Municipal Undertakings have considerable fields of action, local administration, even with delays and financial problems, is increasing its responsibilities, so the Municipality of Kallithea could affect the quality of life in Kallithea to a greater extent.

The connection of the Municipality of Kallithea with the NGOs operating in the city, as well as the fields of their activities, cover and complement municipal policies [30], can create considerable potential and opportunities for the improvement of its nature [31].

This study showed that, in their majority, citizens consider that the municipality has not contributed to the positive characteristics of Kallithea, however few these may be. Citizens consider that positive elements for the city are more of cheap accommodation and employment opportunities and less aesthetic subjects and environmental quality like lack of green, noise etc. Citizens also believe that the municipality has not developed significant activity in major issues such as the protection of the environment. Many residents are not even aware of the existence of most of the municipality's legal entities, and in particular the most important of these, the Municipal Undertakings, which can be funded for such actions. Citizens are also unaware of whether the municipality is using EU funds. The above show that the contribution of the Municipality of Kallithea towards the formation of the city's physiognomy is judged as insignificant by the residents. It is believed by the great majority of its residents that the Municipality of Kallithea can contribute to the improvement of the nature of the city, the perceptual image of visitors and the feeling of identification of the residents with their city.

On the other side, from the interview sent to the authorities of the Municipality of Kallithea, the municipality's attempt to integrate policies and actions that promote the preservation or enhancement of the physiognomy of the city was revealed. The effort for the emergence of a 'good physiognomy' was also revealed.

That emerged from the actions on environmental protection and enhancement components compatible with the physiognomy of the area (e.g. planting of appropriate plants), but also from an attempt to preserve the historical memory and culture (renovation of historic buildings, monuments by et al.). 
Of course, these actions are not high in number and not always clearly orientated towards the protection and enhancement of the city's physiognomy. However, they are in the right direction and serve - though not always consciously - this goal.

In connection with these data, the survey of the sources found that a similar situation prevails in other European urban areas. In the above text, the results and the method for the detection of the opinion of citizens for the actions of the municipality are listed. Also the opinion of the Municipality authorities on these issues is recorded. Thus, both the way of operation and the research results can be taken into account and can be applied to other urban areas which have equally similar characteristics with those of Kallithea. Such areas could be the urban east prefecture of Attica [32, 33], and other Mediterranean cities like Aspropirgos [34] and the city of Volos [35].

\section{REFERENCES}

[1] Stefanou, I., The Nature of a Place, National Metsovian University (NMU): Athens, pp. 17, 41, 2001.

[2] Stefanou, I., The nature of the Greek town, Athens: NMU and Hellenic Ministry for the Environment. Physical Planning and Public Works (MINENV), pp. 9, 13, 15, 24, 71, 83-103, 149, 199, 2000.

[3] Patronis, G., Space-Time-Nature. Interdependence of these three elements and effect on the nature of a town, Case Study: The town of Patras and its nature, Dissertation: NMU pp. 7-19, 26-28, 2003.

[4] Gospodini, A., European cities and place identity. Discussion Paper Series, 8(2), pp. 19-36, 2002.

[5] Helsley, R W., Strange Strategic Growth Controls Regional Science and Urban Economics, No 25, p 436, 1994.

[6] Rossi, A., The Architecture of the Town, Sigxrona Themata publications: Athens, 1987.

[7] Mitoula, R., Nature of the Greek town and institutional framework, 2003.

[8] Brugmann J. "Who can deliver Sustainability? Municipal Reform and the Sustainable Development Mandate", Third World Planning Review Journal, p. 117, 1994.

[9] United Nations, Habitat Agenda And Istanbul Declaration, pp. 34, 81-81, 87-90, 100-103, 107-108, 115, 117-123, 149-150, 1996.

[10] Triantafillidis, Tr., Town Of Kallithea, Kallithea Newspaper publications: Athens, pp. 15-16, 19, 169-177, 183-185, 187, 209, 213, 217-219, 242-243, 1972.

[11] Mitoula, R., Conditions of Modern Greek Town Formation, Sideris publications: Athens, pp 41-87, 2000.

[12] Fileleftheri Ekfrasi publication of the Democracy Institute of Kon. Karamanlis pp. 99-112.

[13] Psalidopoulos, Th., Kallithea. Pages of History and Politics, Anna Andreatidou publications: Kallithea, pp. 17-18, 22, 28, 93-94, 103-110, 274-276, 292, 2002.

[14] Kehagioglou, M., Old Buildings in Kallithea, pp. 3-5, 8-11, 24,26,28-30, 2001.

[15] Karnavos, D., Kallithea Identity and Local Administration, Tsoukatos publications: Athens, p. 169, 2006.

[16] Aravantinos, A., Town Planning, p. 26, 1986.

[17] Papazoglou, Chr., Kallithea of yesterday and today, Erevna publications: Athens, pp. 12, 15-16, 18-33, 74, 100, 149, 225, 288, 352, 490-495, 512, 514, 2000.

[18] Psalidopoulos, Th., Texts on the Town and Culture, Kallithea, p. 35, 2002.

[19] Armirou, K. \& Koukiou, E., Old Industries and Workshops in Kallithea, Harokopio University, Graduate Study: Athens, pp. 3-11,29, 66-69, 2003.

[20] Hlepas, K., Perspectives of Local Democracy, Sakkoula publications: Athens, 1998. 
[21] Fanariotis, P., Before The Challenges of the 21st Century: Public Administration Decentralisation and Local Administration, Stamoulis publications: Athens, 1999.

[22] Delitheou, V., Summary Notes from Lectures. Course: Local Development and Self Administration - Institutional Framework - Development Programmes and Globalisation, Harokopio University: Athens, pp. 66, 133-134, 160, 171, 173, 2004.

[23] Municipality of Kallithea, Report on the Fund Account Chart of the Municipality of Kallithea, Fiscal Year 2005, Municipality of Kallithea: Kallithea, 2007.

[24] Centre for Accompanying Support Services, Kallithea, Orientation, Employment, Integration, Information, Support, Municipality of Kallithea: Kallithea, pp. 2-4, 2004.

[25] Simmons, P.J., Learning to Live with NGO, Foreign Policy, p. 83, 1998.

[26] Karnavos, D., Kallithea NGOs: categorisation and contribution to the formation of its nature. Local Administration and Peripheral Development Decentralisation Review, Issue 43: Athens, pages 63-70, 2006.

[27] Pitsoulis, N., Role and operation of NGOs at the dawn of the 21st century, Ethelontiki Ekfrasi, Issue 1, pp. 18-21, 2003.

[28] Lazaris, E., The necessity for improved structuring systems in the building sector, www.cres. gr., 2004.

[29] www.pepatt.gr.

[30] Kousianakou, M., Scenario study and pre-study of a complete programme for development and regulation of the Beach-Hippodrome zone A' \& B' Phase, Municipality of Kallithea pp. 12, 12, 21-24, 26-29, 36, 38, 46-48, 49, 58-59, 61-62, 64,70, 2002- 2003.

[31] Sklias, P. \& Houliaras, A., Diplomacy of the Society of Citizens, Papazisis publications: Athens, pp. 13-15, 2002.

[32] Theodoropoulou, M., Mitoula, R., Vamvakari, M., Urban development in east prefecture of attica, greece. Social and economic changes during the summer of the year 2004. Journal: Housing \& Building Research Center (HBRC Journal), 5, No 2, 2009a.

[33] Theodoropoulou, M., Mitoula, R., Vamvakari, M., Community development in the east prefecture o Attica, Greece, following the 2004 summer olympic games of Athens. International Journal of Sustainable Development and Planning, WITPRESS, 2, pp. 112-122, 2009b.

[34] Mitoula, R., Filippou, K, Lagos, D., Sustainable development and environmental reconstruction in the municipality of aspropyrgos in Greece. International Journal of Academic Research, 2(1), ISSN: 2075-4124, pp. 177-185, 2010.

[35] Theodoropoulou, H., Mitoula, R., Vamvakari, M. Efthimiou, Th., The Mediteranian Games of 2013, as a vaulting horse for Sustainable Development for the city of Volos", Proceedings for the International Conference on Urban Planning \& Regional Development. CORP 2010. Liveable, healthy, Prosperous Cities for Everyone. 18-20 May 2010, Vienna, Austria, pp. 745-755, 2010.

[36] Pippos, Ch., EU policy on Renewable Energy Sources and Energy Saving in the building sector- Community Directive 2002/91/EK on the improvement of building energy efficiency, www.cres.gr., 2004.

[37] Basic Town Planning Code- 1999.

[38] Mitoula, R., Policies and Actions of the European Union on urban reconstitution and peripheral development - Their consequences on the Greek town, Harokopio University, pp. 67-73, 77, 179-91, 197, 141-46, 152, 161-68, 2004. 